Adıyaman Üni. Sağlık Bilimleri Derg, 2015; 1(3):169-174

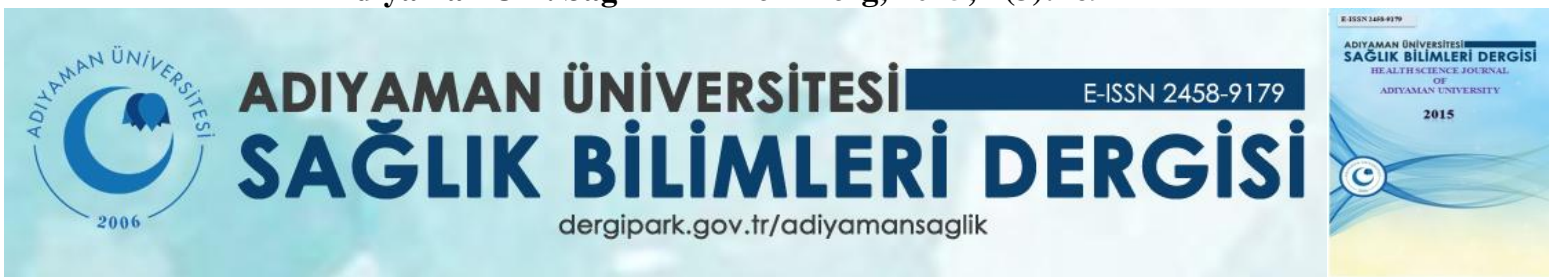

Olgu sunumu / Case report

\title{
Intrauterin Dönemde Tespit Edilen Konjenital Diafram Hernisi: Olgu Sunumu
}

(Pursuence of a patient who is congenital diaphragm hernia. Case presentation)

\section{Pervin KARLI ${ }^{1}$, Osman Fadıl KARA ${ }^{1}$}

${ }^{1}$ Amasya Üniversitesi Tıp Fakültesi Kadın Hastalıkları ve Doğum Anabilim Dalı.

\section{ÖZET:}

Konjenital diyafram hernisi (KDH) 1/2200 insidansı ile nadir görülen bir konjenital anomalidir. Biz vakamızda 24. gebelik haftasında tespit ettiğimiz konjental diafragma hernisinin Çocuk Cerrahi kliniği ile birlikte doğuma kadar takibi, doğum sonrası yenidoğan viabilitesi ve 12 ay sonra yapılan kontrol takiplerinin sonuçlarını değerlendirdik.

Anahtar Kelimeler: Konjenital diyafragma hernisi, Morgagni, Erken tanı.

\begin{abstract}
Congenital Diaphragm Hernia is a congenital abnormality seen rarely with (KDH) 1/2200 incidence. In the event, we have realized the pursuance of congenital diaphragm hernia we have ascertained in 24th pregnancy week with Clinic of Pediatric Surgeon, new-born viability after birth and have determined the results of the control pursuance made 12 months after birth.
\end{abstract}

Keywords: Kongenital diaphragm hernia, pregnancy, early diagnosis.

\begin{tabular}{l}
\hline Yazışmadan Sorumlu Yazar \\
\hline Pervin KARLI \\
Amasya Üniversitesi Tıp Fakültesi Kadın Hastalıkları ve \\
Doğum Anabilim Dalı \\
Tel : +90 05056959485 \\
Email: parpi2300@ hotmail.com \\
\hline
\end{tabular}

\begin{tabular}{ll}
\hline Geliş Tarihi: & 12.09 .2017 \\
\hline Kabul Tarihi: & 30.11 .2017 \\
\hline
\end{tabular}




\section{GİRIŞ:}

Konjenital diafragma hernisi $(\mathrm{KDH})$ abdominal organların diafragmatik bir defekten torasik kaviteye doğru protrüzyonu ile karakterizedir. İnsidansı 2200 canlı doğumda bir olup, yüksek derecede mortalite ve morbidite ile birliktelik gösterir (1). KDH'de diaframdaki defekt \%80-85'inde sol posterolateralde (Bochdalek), \%10-15 olguda anteriorda (Morgagni), \%3-4 olguda bilateraldir (2). Bu lezyonlar genellikle yenidoğan dönemde ciddi solunum sıkıntısıyla kendini gösterir. "Congenital Diaphragmatic Hernia Study Group" tarafından dünyadaki 51 merkez verilerini değerlendiren bir çalışmada taburcu öncesi genel mortalite oranı \% 31 olarak bulunmuştur (3). KDH'lerin \% 40-60'1 antenatal ultrasonografi ile tespit edilebilmektedir (4).

$\mathrm{Bu}$ çalışmada, 24. gebelik haftasında yapılan ultrasonografide, fetüs mide gölgesinin kalbin yanında izlendiği ve sonrasında diafragma hernisi tablosunun belirginleştiği, postnatal dönemde diafragma hernisi tanısı konularak çocuk cerrahisi kliniği tarafından opere edilen diafragmatik herni olgusu sunulmuştur.

Ağır olgularda, genellikle yenidoğan döneminde kayıplar olmakta ve ebeveynler ciddi bir psikolojik travmaya maruz kalmaktadırlar. $\mathrm{Bu}$ nedenle, bu olguların intrauterin dönemde tanısının konulması ve gestasyonel haftaya gore tedavi stratejisinin belirlenmesi önemlidir.

\section{OLGU SUNUMU:}

26 yaşında ilk gebeliği olan hastanın, yapılan ilk trimester trizomi tarama testinde Free Beta hCG değeri $6 \mathrm{MoM}$ (multiples of median) ve risk oranı 1/489 olarak bulundu ve ense kalınlığı (nuchal translucency, NT) ölçümü 1,1 mm olarak ölçüldü. Hastaya 24. gebelik haftasında yapılan ultrasonografide, mide gölgesi kalbin yanında izlendi ve diğer fetal yapılar 
normal olarak değerlendirildi (Şekil 1). Yapılan 31. hafta ultrasonografisinde kalbin yanında mide gölgesinin daha fazla belirginleştiği görüldü.(şekil 2).

Hastanın ilerleyen haftalardaki ultrasonografik takiplerinde, kalbin yanında gözlenen mide gölgesinin daha fazla belirginleştiği görülmüştü. Hasta Çocuk Cerrahisi ve Kadın Hastalıkları Kliniği'nin olduğu bir merkeze sevk edilerek daha sonra 37. gebelik haftasında bu merkezde sezaryen ile doğum yaptırılmış, 2580 gr. ağırlığında kız bebek doğduktan sonra solunum sıkıntısı sebebiyle yenidoğan yoğun bakım servisinde entübe edilmiş olduğu, bebeğin ön-arka akciğer grafisinde sol hemitoraksı dolduracak şekilde gastrointestinal sisteme ait hava gölgeleri izlenmiş olduğu ve hasta 1 günlükken konjenital diafragma hernisi nedeniyle opere edilmiş ve eksplorasyonda sol posterolateral diafragma hernisi olduğu bilgisi tarafımıza bildirilmiştir. Toraks boşluğuna herniye olan tüm ince barsaklar, mide ve karaciğer sol lobu batın içine redükte edilmiş, herni kesesi eksize edilerek defekt primer olarak onarılmış ve hasta postoperatif 20. günde şifa ile taburcu edilmiş ve oniki aylık takibinde herhangi bir problemi izlenmemiştir.

\section{TARTIŞMA:}

$\mathrm{KDH}$ nedenleri tam olarak bilinmemekle birlikte, bir veya daha fazla genle ilişkili olduğuna inanılır. A vitamini eksikliği, anti epileptik ilaçlar, Talidomid gibi bazı teratojen faktörler ileri sürülmektedir (5). Genelde sporadiktir, ancak \% 2'si ailesel olarak ortaya çıkmaktadır (6). Bizim olgumuzun anamnezinde ilaç kullanımı ve ailesel bir öykü yoktu. Sol taraftaki diafragma hernilerinde $\% 85$ 'inde karaciğer heniasyonu tespit edilmiş olmasına rağmen akciğerlerle karaciğerin ekojeniteleri birbirine çok yakın olduğundan karaciğer herniasyonunun tanısı zordur (5). Nitekim bizim olgumuzda da karaciğer herniasyonu izlenmesine rağmen prenatal ultrasonografide karaciğer herniasyonuna ait bulgu saptanmadi. 
Genellikle gestasyonun 24. haftasından sonra ultrasonografi ile KDH'ni tespit edebilme oranı \%59'dur ve bu oran ilerleyen gestasyonel yaş ve eşlik eden diğer anomali varlığında $\operatorname{artar}$ (7). Doğum öncesi tanı 24. haftanın öncesinde \%22-52 oranında koyulabilir. Ancak 24.gebelik haftasından sonra bile tanı koyulması zor olarak kabul edilir, çünkü \%25 vaka gözden kaçmakta ve \%11 vaka doğum sonrası tanı almaktadır (8).

Konjenital diafragma hernisi daha sıklıkla sol tarafta olduğundan tanıda en önemli bulgu toraksın sol tarafında kistik kitlenin varlığı ve midenin gözlenememesidir. Diğer bulgular kalbin sağa deviasyonu ve polihidramniozdur $(5,9)$. Bizim olgumuzda polihidramnioz yoktu ve abdomende normal pozisyonda sıvı dolu mide olmadığ 1 , kalbin mediasten boyunda sağ tarafa yer değiştirdiği sol hemitoraksta sıvı dolu mide gölgesinin kalbe komşu olarak izlendiği tespit edildi.

Gestasyonun 24. haftasından önce konjenital diafragmatik herni tanısı alan fetüslerin \%60'ının yaşamlarını kaybettikleri bilinmektedir (4). Bu yüzden antenatal tanı konulması yenidoğan ölümlerinin önlenmesi açısından önemlidir.

KDH de prenatal tanı; hastanın takip ve tedavisinin planlanması, doğum sonrası gerekecek olan yoğum bakım, cerrahi gerekliliği açısından doğru yönlendirilmesi ve yenidoğan a doğumdan hemen sonra cerrahi yapılabilecek bir merkezde değil ise o merkeze için sevki için uygun zaman diliminin sağlanması açısından önem arz etmektedir. 


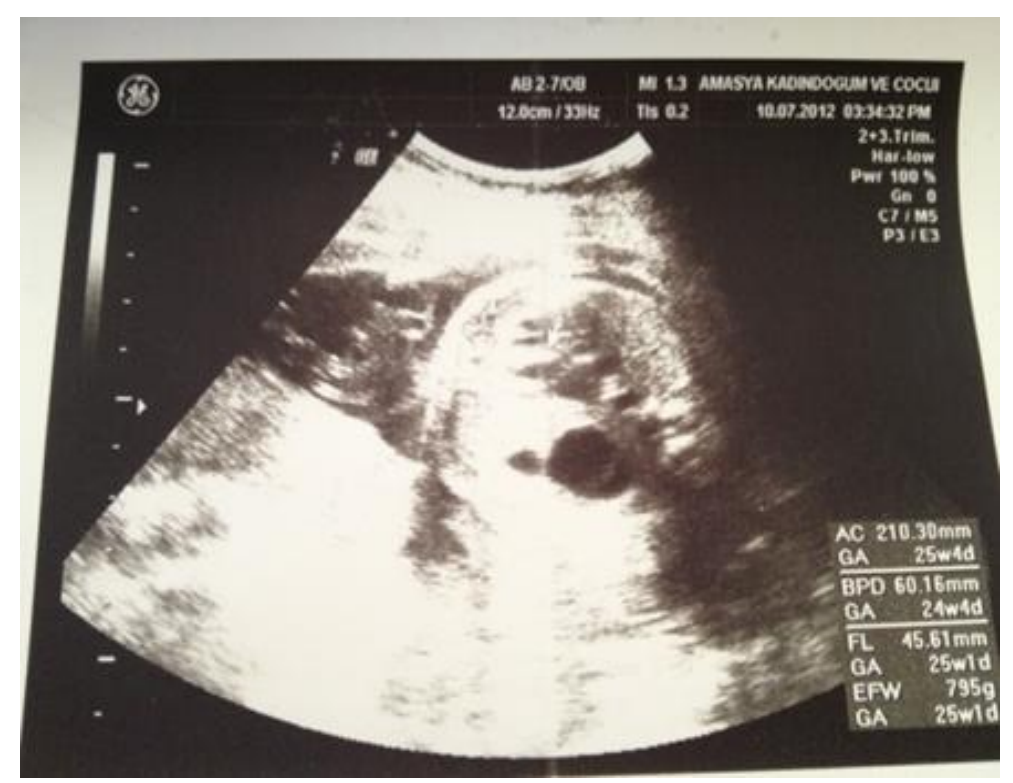

Şekil I: 24. gebelik haftasında kalbin görüntülendiği alanın yanında mideye ait gölgelenme görülüyor.

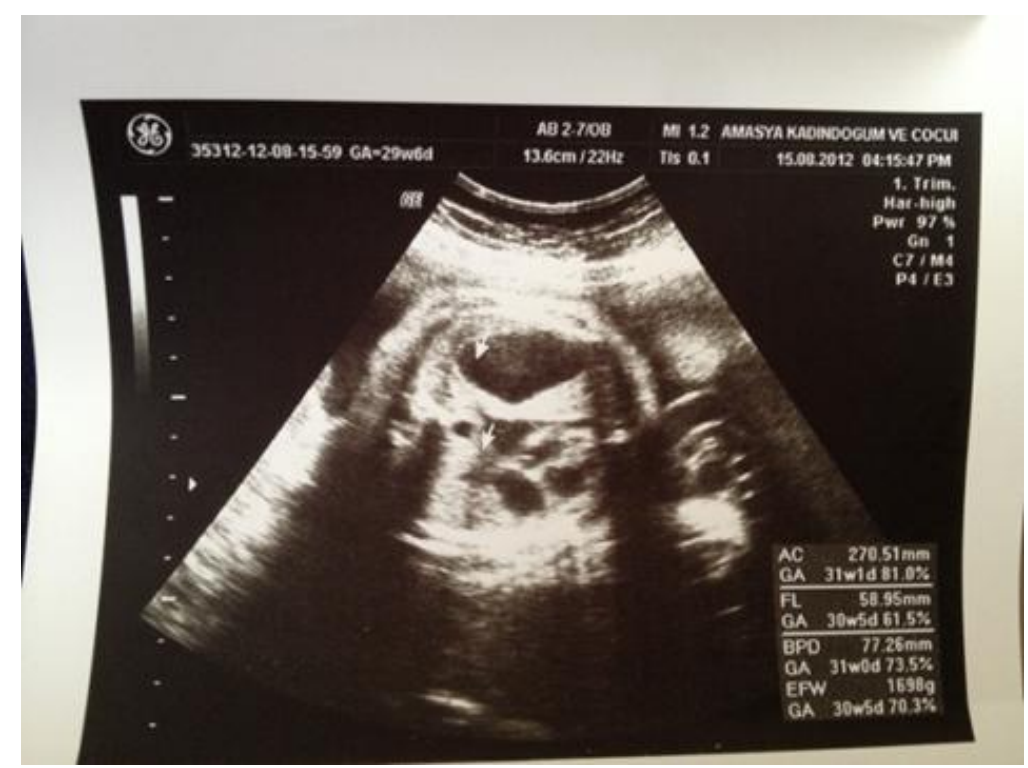

Şekil II: 31. gebelik haftasında kalbin yanında görünen mide gölgesinin daha fazla belirginleştiği görülüyor. 


\section{KAYNAKLAR}

1. Graham G, Devine PC: Antenatal diagnosis of congenital diaphragmatic hernia. Seminars in perinatology $2005 ; 29(2): 69-76$.

2. Butler N, Claireaux AE: Congenital diaphragmatic hernia as a cause of perinatal mortality. Lancet 1962;1(7231):659-63.

3. Lally KP, Lally PA, Lasky RE et al: Defect size determines survival in infants with congenital diaphragmatic hernia. Pediatrics 2007;120(3):651-7.

4. Başaklar AC: Konjenital Diafram Hernileri. In: Bebek ve Çocukların Cerrahi ve Ürolojik Hastalıkları. edn. Edited by Başaklar AC. Ankara: Palme; 2006, s. 273-309.

5. Paladini D: Ultrasound of Congenital Fetal Anomalies. In., 1. edn. Edited by Paladini D VP. London; 2007, s.187-92.

6. Beurskens LW, Tibboel D, Lindemans J et al: Retinol status of newborn infants is associated with congenital diaphragmatic hernia. Pediatrics 2010;126(4):712-20.

7. Garne E, Haeusler M, Barisic I et al: Congenital diaphragmatic hernia: evaluation of prenatal diagnosis in 20 European regions. Ultrasound in obstetrics \& gynecology : the official journal of the International Society of Ultrasound in Obstetrics and Gynecology 2002;19(4):329-33.

8. Gallot D, Coste K, Francannet C, et al: Antenatal detection and impact on outcome of congenital diaphragmatic hernia: a 12-year experience in Auvergne, France. European journal of obstetrics, gynecology, and reproductive biology 2006;125(2):202-5.

9. Muzzafar S, Swischuk LE, Jadhav SP: Radiographic findings in late-presenting congenital diaphragmatic hernia: helpful imaging findings. Pediatric radiology 2012;42(3):337-42. 